\title{
SYNTHESIS OF PEPTIDE NUCLEIC ACIDS (PNA) BY SUBMONOMER SOLID-PHASE SYNTHESIS
}

\author{
Lutz S. Richter and Ronald N. Zuckermann* \\ Chiron Corporation, 4560 Horton Street, Emeryville, CA 94608
}

\begin{abstract}
A simple, versatile method for the synthesis of Peptide Nucleic Acids (PNA) from readily available building blocks has been developed. The approach is based on submonomer solid phase synthesis and allows for the structural variation of both the backbone and the nucleobase sidechain. The efficiency of the method was demonstrated by the synthesis of PNA oligomers in high purity and good yields.
\end{abstract}

Peptide Nucleic Acids (PNA), oligonucleotide analogs with an achiral \{oligo-N-(2-aminoethylglycine) \} backbone, have been shown to specifically recognize the complementary sequence of oligonucleotide oligomers. ${ }^{1}$ Moreover, PNA/oligonucleotide hybrids are thermally more stable than the corresponding DNA (or RNA) hybrids, ${ }^{2}$ and they should possess increased biological stability. ${ }^{3}$ Therefore, PNA molecules have potential for the development of gene-targeting pharmaceuticals and as antagonists for proteins that recognize DNA. ${ }^{4}$

In this communication, we describe a simple and highly versatile method for the synthesis of PNA oligomers. Using a "submonomer" approach,5 PNA molecules were synthesized on polystyrene resin from inexpensive precursors like bromoacetic acid, a protected ethylenediamine (e.g., 4-methoxybenzyloxycarbonyl (Moz) - ethylenediamine), and a nucleobase derivative (e.g., 1-carboxymethyl-thymine; ${ }^{6}$ Scheme 1 ). In contrast to the original approach for the synthesis of PNA oligomers, ${ }^{1}$ the solution-phase synthesis of N-protected, nucleobase-substituted aminoethylglycine-monomers is not required. As a consequence, the overall synthesis is less expensive, and PNA derivatives with variations in the backbone or at the site of the nucleobase can be synthesized readily.

Optimized protocols for the acylation of a resin-bound primary or secondary amine with bromoacetic acid and for the subsequent displacement step have been published earlier. ${ }^{5}$ As expected, these conditions could be directly applied to PNA synthesis. However, acylation of the resin-bound secondary amine 3 with 1carboxymethyl-thymine proved to be inefficient under most common acylation conditions. ${ }^{7}$ This was partly due to solubility properties of 1-carboxymethyl-thymine in most organic solvents. In addition, intra-chain association of the highly functionalized, very polar PNA strand could prevent quantitative acylation of 3 .

After some optimization effort, we found that the desired acylation of the secondary amine 3 proceeds very efficiently when PyBroP ${ }^{8}$ is used as an activating agent in a 1:1-mixture of dimethylsulfoxide (DMSO) and $\mathrm{N}$-methylmorpholine (NMM). In fact, under the conditions described below, the acylation of 3 proved to be more efficient than the displacement of 2 with $0.5 \mathrm{M} \mathrm{Moz-ethylenediamine} \mathrm{in} \mathrm{dimethylsulfoxide,}{ }^{9}$ as evidenced by mass spectrometry analysis of contaminants. 


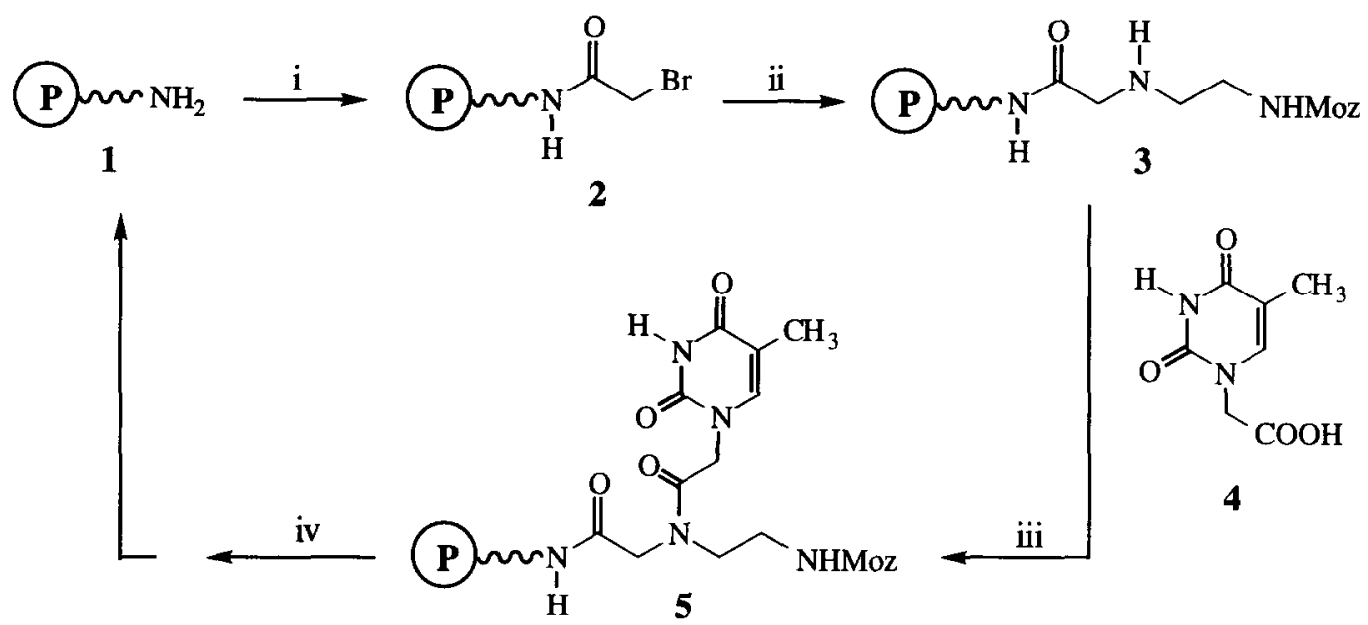

Scheme 1. Synthesis of PNA oligomers by submonomer solid phase synthesis. (i) bromoacetic acid, diisopropylcarbodiimide, dimethylformamide (DMF), $30 \mathrm{~min}$; (ii): Moz-ethylenediamine, DMSO, $2 \mathrm{~h}$; (iii) PyBroP, 4, N-methylmorpholine/DMSO, $30 \mathrm{~min}$; (iv) trifluoroacetic acid (TFA), thioanisole, ethanedithiol, dichloromethane, $10 \mathrm{~min}$, then triethylamine, dichloromethane, $10 \mathrm{~min}$.

After TFA-induced cleavage from the solid support ${ }^{11}$ and HPLC purification, the products were characterized by mass spectrometry. In addition, a hybridization experiment of a PNA-octamer $\left(\mathrm{Ac}-\mathrm{T}_{8}-\mathrm{NH}_{2}\right)$ with a complementary DNA-decamer $\left[(\mathrm{dA})_{10}\right]$ was performed. The melting temperature was found to be $\mathrm{T}_{\mathrm{m}}=58^{\circ} \mathrm{C}$ (Figure 1), confirming the exceptional thermal stability of PNA-DNA-hybrids. 12

In order to minimize subsequent purification problems, we capped unreacted bromoacetamide with sulfides like $p$-nitrothiophenol or $p$-nitrobenzylthiol ${ }^{10}$ in the presence of a tertiary amine like NMM. Under these synthesis conditions, we obtained highly pure PNA oligomers (Figure 1).

(a)

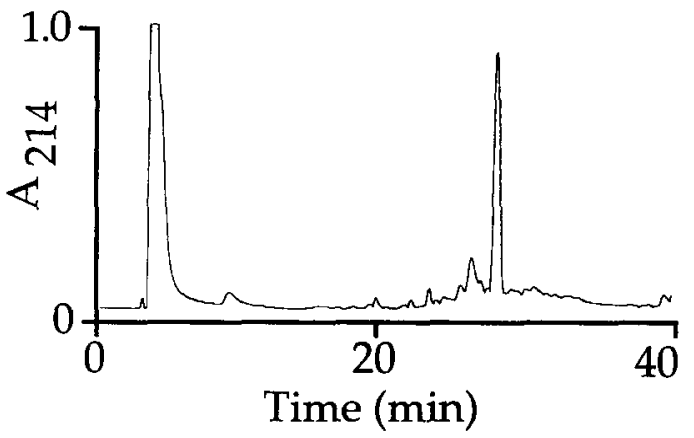

(b)

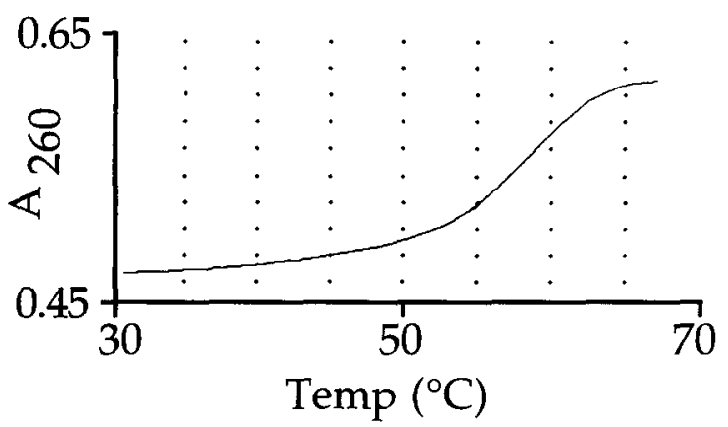

Figure 1. (a) HPLC chromatogram of a crude PNA pentamer and (b) melting curve of $A c-\mathrm{T}_{8}-\mathrm{NH}_{2}$ with (dA) 10 . 
In summary, we have demonstrated that homothymine PNA oligomers can be efficiently synthesized from inexpensive starting materials using the submonomer method. ${ }^{5}$ It can be envisioned that suitably protected ${ }^{13} \mathrm{~N}$-carboxymethyl analogs of adenine, guanine and cytosine should allow for the synthesis of PNAmolecules containing all 4 nucleobases. Similarly, a wide variety of heterocyclic compounds can be incorporated, and derivatives with structural modifications at the backbone should also be easily accessible.

Acknowledgment. The authors would like to thank Dr. T. Horn for many helpful discussions, Dr. S. Kaur for mass spectrometry analyses, and J. Kerr and C. Cushman for valuable assistance.

Experimental. Analytical HPLC was performed on a Rainin HPX system with a C18 reversed-phase HPLC column (Vydac, $25 \mathrm{~cm} \mathrm{x} 4.6 \mathrm{~cm}$ ) and a gradient elution (solvent $\mathrm{A}: \mathrm{H}_{2} \mathrm{O} / 0.1 \%$ TFA; solvent B: $\mathrm{CH}_{3} \mathrm{CN} / 0.1 \%$ TFA; $0-25 \%$ B in $40 \mathrm{~min}$ ). Electrospray mass spectra were acquired on a Sciex API-III triple-quadrupole mass spectrometer (Perkin-Elmer Sciex Instruments, Thornhill, Canada). Melting temperature of hybrids were determined on a Varian Cary $3 e$ spectrophotometer in $10 \mathrm{mM} 50 \mathrm{mM}$ MOPS, $140 \mathrm{nM} \mathrm{NaCl}, 10 \mathrm{mM} \mathrm{MgCl}$, $\mathrm{pH}$ 7.0 , at a heating rate of $1^{\circ} \mathrm{C} / \mathrm{min}$. The following extinction coefficients were used: $A, 15.4 ; T, 8.8$.

\section{Synthesis of Submonomers:}

Moz-ethylenediamine: To a stirred solution of ethylenediamine $(12.02 \mathrm{~g}, 200 \mathrm{mmol})$ in dichloromethane (200 $\mathrm{mL})$, a solution of 4-methoxybenzyloxycarbonyl azide $(10.36 \mathrm{~g}, 50 \mathrm{mmol})$ in dichloromethane $(200 \mathrm{~mL})$ was added dropwise at room temperature, and stirring was continued for 7 hours at room temperature. The crude mixture was washed with water $(2 \times 100 \mathrm{~mL})$ and extracted with a solution of glacial acetic acid $(3.5 \mathrm{~g})$ in water $(80 \mathrm{~mL})$. The organic layer was re-extracted with glacial acetic acid $(0.5 \mathrm{~g})$ in water $(30 \mathrm{~mL})$, and the combined aqueous layers were brought to $\mathrm{pH} 8.5$ with a $10 \%$ aqueous solution of $\mathrm{Na}_{2} \mathrm{CO}_{3}$. The product was kept at $0^{\circ} \mathrm{C}$ for 16 hours, and filtered with suction to give $6.0 \mathrm{~g}(54 \%)$ of white crystals. ${ }_{\mathrm{H}} \mathrm{NMR}\left(\mathrm{d}_{6}-\mathrm{DMSO}\right): \delta=2.35$ (br; $\left.2 \mathrm{H}, \mathrm{NH}_{2}\right), 2.50\left(\mathrm{t}, \mathrm{J}=7 \mathrm{~Hz} ; 2 \mathrm{H}, \mathrm{CH}_{2}\right), 3.93\left(\mathrm{dt}, \mathrm{J}_{1}=\mathrm{J}_{2}=7 \mathrm{~Hz} ; 2 \mathrm{H}, \mathrm{CH}_{2}\right), 3.70\left(\mathrm{~s} ; 3 \mathrm{H}, \mathrm{OCH}_{3}\right), 4.88$ $\left(\mathrm{s} ; 2 \mathrm{H}, \mathrm{OCH}_{2}\right), 6.87$ and $7.24(2 \mathrm{~d}, \mathrm{~J}=11 \mathrm{~Hz} ; 4 \mathrm{H}$, arom. $\mathrm{H}), 7.13(\mathrm{t}, \mathrm{J}=7 \mathrm{~Hz} ; \mathrm{NH})$.

1-carboxymethyl-thymine ${ }^{6}$ (4): A solution of 1-cyanomethyl-thymine in $500 \mathrm{~mL}$ of $1.0 \mathrm{M}$ aqueous $\mathrm{KOH}$ was refluxed for 2 hours. Concentrated $\mathrm{HCl}(45 \mathrm{~mL}$; caution!) was added while the reaction mixture was still hot ( $\mathrm{pH}=2-3$ after $\mathrm{HCl}$ addition), and the mixture was allowed to slowly cool down to room temperature and kept at $0^{\circ} \mathrm{C}$ for 16 hours. The product was filtered and dried; yield $20.2 \mathrm{~g}(88 \%)$ of white crystals. ${ }^{1} \mathrm{H}$ NMR ( $\mathrm{d}_{6}$ DMSO): $\delta=1.76\left(\mathrm{~s} ; 3 \mathrm{H}, \mathrm{CH}_{3}\right), 4.36\left(\mathrm{~s} ; 2 \mathrm{H}, \mathrm{CH}_{2}\right), 7.49(\mathrm{~s} ; 1 \mathrm{H}, 4-\mathrm{H}), 11.34(\mathrm{~s}, 1 \mathrm{H}, \mathrm{NH}), 13.15(\mathrm{~s} ; 1 \mathrm{H}$, $\mathrm{COOH})$.

\section{Submonomer Solid-Phase Synthesis of PNA oligomers:}

All reactions were performed at room temperature using $50 \mu \mathrm{mol}$ (approx. $100 \mathrm{mg}$ ) of N-Fmoc-4-methoxy-4'( $\gamma$ carboxypropyloxy)-benzhydrylamine resin. ${ }^{11}$ Prior to synthesis, the resin was deblocked (20\% piperidine in DMF, $1 \times 20 \mathrm{~min})$ and washed with DMF ( $3 \times 1 \mathrm{~mL})$. Before and after each reaction step, the resin was washed with the reaction medium $(3 \times 1 \mathrm{~mL})$. Agitation with argon gas was used to ensure proper mixing of resin, reagents and solvents. Cleavage was accomplished ${ }^{11}$ with $95 \%$ aqueous TFA at $40^{\circ} \mathrm{C}$ for $60 \mathrm{~min}$.

(a) Bromoacetylation of the $N$-terminus:

$830 \mu \mathrm{L}$ of $0.6 \mathrm{M}$ bromoacetic acid in DMF, $200 \mu \mathrm{L}$ of $3.2 \mathrm{M}$ diisopropylcarbodiimide in DMF, $2 \times 30$ min.

(b) Displacement of resin-bound bromoacetamides with Moz-ethylenediamine: $1.0 \mathrm{~mL}$ of a $0.5 \mathrm{M}$ solution of Moz-ethylenediamine in DMSO, $1 \times 2$ hours. 
(c) Capping of unreacted bromoacetamide: $100 \mathrm{mg}$ 4-nitrothiophenol in DMF $(800 \mu \mathrm{L}) / \mathrm{NMM}(100 \mu \mathrm{L}), 1 \times 30 \mathrm{~min}$.

(d) Acylations with 1-carboxymethyl-thymine: solid PyBroP (233.5 mg, $0.5 \mathrm{mmol}$ ), $1.0 \mathrm{~mL}$ of $0.5 \mathrm{M}$ 1-carboxymethyl-thymine in DMSO/NMM (1:1), $2 \times 30 \mathrm{~min}$.

(e) Removal of the Moz-group: $1.0 \mathrm{~mL}$ of $5 \%$ trifluoroacetic acid, $2.5 \%$ thioanisole and $2.5 \%$ ethanedithiol in $90 \%$ dichloromethane, $1 \mathrm{x}$ $10 \mathrm{~min}$.

(f) Neutralization: $1.0 \mathrm{~mL}$ of $10 \%$ triethylamine in dichloromethane, $1 \times 10 \mathrm{~min}$.

(g) Acetylation of the $\mathrm{N}$-terminus: dichloromethane $(800 \mu \mathrm{L})$, acetic anhydride $(100 \mu \mathrm{L}), \mathrm{NMM}(100 \mu \mathrm{L}), 2 \times 10 \mathrm{~min}$.

\section{References:}

1. (a) Egholm, M.; Buchardt, O.; Nielsen, P. E.; Berg, R. H. J. Am. Chem. Soc. 1992, 114, 1895; Egholm, M.; Nielsen, P. E.; Buchardt, O.; Berg, R. H. J. Am. Chem. Soc. 1992, 114, 9677.

2. Egholm, M.; Buchardt, O.; Christensen, L.; Behrens, C.; Freier, S. M.; Driver, D. A.; Berg, R. H.; Kim, S. K.; Norden, B.; Nielsen, P. E. Nature 1993, 365, 566.

3. Hyrup, B.; Egholm, M.; Nielsen, P. E.; Wittung, P.; Nordén, B.; Buchardt, O. J. Am. Chem. Soc. 1994, 116,7964 .

4. Uhlmann, E.; Peyman, A. Chem. Rev. 1990, 90, 544.

5. Zuckermann, R. N.; Kerr, J. M.; Kent, S. B. H.; Moos, W. H. J. Am. Chem. Soc. 1992, 114, 10646.

6. (a) Siegel, S. A., Lin, T. S. Biochem. Pharmacol. 1985, 34, 1121; (b) Wittenburg, E. Chem. Ber. 1966, $99,2380$.

7. Activation using diisopropylcarbodiimide in a variety of solvents (e.g., dichloromethane, DMF) failed to provide a PNA-dimer in $>10 \%$ purity. PyBroP-activation was most efficient in DMSO/NMM, followed by DMSO/DIEA and DMF/DIEA. PyBroP/DIEA in dichloromethane gave unsatisfactory results.

8. Coste, J.; Frérot, E.; Jouin, P.; Castro, B. Tetrahedron Lett. 1991, 32, 1967.

9. Displacement reactions of resin-bound bromoacetamides with primary amines are typically quantitative when a $2.0 \mathrm{M}$ solution of amine in DMSO is used (see Zuckermann, R. N.; Goff, D. A. Polymer Preprints 1994, 35, 975). However, the solubility properties of Moz-ethylenediamine only allow concentrations of up to a $0.5 \mathrm{M}$ to be used. Elevated temperatures during the displacement step should increase solubility and yield. Alternatively, the use of a different protecting group could overcome solubility problems.

10. $p$-Nitrophenyl-substituted mercaptans were chosen because of their characteristic UV-absorption which allows for facile detection.

11. An Fmoc-4-methoxy-4' ( $\gamma$-carboxypropyloxy)-benzhydrylamine linker on alaninyl-aminomethyl polystyrene resin (Bachem Bioscience, Inc.) was used. Cleavage was accomplished with $95 \%$ aqueous TFA at $40^{\circ}$ C; see W. Stueber, J. Knolle, G. Breipohl. Int. J. Peptide Protein Res. 1989, 34, 215.

12. Homopurine DNA strands have been shown to form thermally stable triplexes with homopyrimidine PNA strands ${ }^{1 \mathrm{a}-\mathrm{b}}$. Since the $\mathrm{T}_{\mathrm{m}}$ of $A c-\mathrm{T}_{8}-\mathrm{NH}_{2}$ with $(\mathrm{dA})_{10}$ lies in the expected range ${ }^{\mathrm{la}}$, we assume a $2: 1$ stoichiometry for the hybrid.

13. Beaucage, S. L.; Iyer, R. P. Tetrahedron 1992, 48, 2223.

(Received in USA 23 March 1995; accepted 20 April 1995) 